\title{
Avaliação das normas de biossegurança em profissionais da saúde de um hospital público e um centro de reabilitação em Aracaju
}

\author{
Evaluation of biosafety standards in health professionals at a public hospital and a rehabilitation
} center in Aracaju city

Evaluación de estándares de bioseguridad en profesionales de la salud de un hospital público y centro de rehabilitación de Aracaju

\section{Resumo}

A biossegurança aborda a prevenção como tópico primordial para os trabalhadores, sobretudo para os profissionais de saúde, devido ao ambiente de trabalho que apresenta maior susceptibilidade aos acidentes. Trata-se de evitar riscos à saúde, através da utilização de equipamentos de proteção individual (EPI) e equipamentos de proteção coletiva (EPC), além dos seguimentos das normas que minimizam as contaminações. Contudo, é necessário ressaltar a importância do conhecimento prévio sobre a biossegurança durante a fase acadêmica para permanecer com os conhecimentos ao longo da fase profissional. Sendo assim, o estudo teve como objetivo avaliar a aplicabilidade das normas de Biossegurança no âmbito hospitalar e ambulatorial. Refere-se a um estudo observacional, transversal e de campo, de natureza quali-quantitativa, executado mediante autorização e assinatura do Termo de Consentimento Livre e Esclarecido pelos profissionais e acadêmicos da saúde. A coleta de dados foi realizada no Centro de Saúde Ninota Garcia e no Hospital de Urgência de Sergipe Governador João Alves Filho. A amostra foi por conveniência, constituída por 114 participantes. Em relação aos resultados alcançados, foi possível evidenciar que os acadêmicos da área da saúde apresentaram maior adesão às normas de biossegurança, enquanto os profissionais necessitam de intervenções que visem atualizar esse conhecimento. Com isso, foram evidenciadas as competências benéficas da atualização frequente das normas preventivas que refletem a adequada utilização de EPI, bem como a redução dos riscos de acidentes, sendo a capacitação das normas de biossegurança condição indispensável tanto para discentes quanto para profissionais da área da saúde.

Palavras-chave: Biossegurança; Contágio; Equipamento de Proteção Individual; Fisioterapia.

\begin{abstract}
Biosafety approaches prevention as a primordial topic for workers, especially health professionals, due to the work environment that presents most susceptibility to accidents. It is about avoiding health risks through the use of personal protection equipment and collective protection equipment, in addition to following the rules that minimize contamination. However, it is necessary to emphasize the importance of prior knowledge about biosafety during the academic phase to remain with the knowledge through the professional phase. Thus, the research aimed to evaluate the applicability of biosafety rules in hospital and outpatient place. This is an observational, cross-sectional, field study, with quali-quantitative nature, carried out after Informed and Free Consent Form signed by the health professionals and academic. Data collection was carried out at Ninota Garcia Health Center and at Governador João Alves Filho Health Emergency Hospital. The sample was by convenience, consisting of 114 participants. Regarding the results achieved, it was possible to show that health academics showed greater adherence to biosafety rules, while
\end{abstract}


professionals need interventions to update their knowledge about safety measures. Thus, they were highlighted as beneficial disadvantages of frequent updating of preventive rules that reflect the use of personal protection equipment, as well as the reduction of the acidentes risk, with training in biosafety rules being an essential condition for students and health professionals.

Keywords: Biosafety; Contagion; Personal Protection Equipment; Physiotherapy.

\section{Resumen}

La bioseguridad aborda la prevención como un tema primordial para los trabajadores, especialmente para los profesionales de la salud, debido al entorno laboral más susceptible a los accidentes. Se trata de evitar riesgos para la salud mediante el uso de equipos de protección individual (EPI) y equipos de protección colectiva (EPC), además de seguir los estándares que minimizan la contaminación. Sin embargo, es necesario enfatizar la importancia del conocimiento previo sobre bioseguridad durante la fase académica para permanecer en el conocimiento durante toda la fase profesional. Por lo tanto, el estudio tuvo como objetivo evaluar la aplicabilidad de los estándares de bioseguridad en el ámbito hospitalario y ambulatorio. Se refiere a un estudio observacional, transversal y de campo, de carácter cuali-cuantitativo, realizado con autorización y firma del Formulario de Consentimiento Informado por profesionales de la salud y académicos. La recolección de datos se realizó en el Centro de Salud Ninota García y en el Hospital de Emergencias Sergipe Governador João Alves Filho. La muestra fue por conveniencia, compuesta por 114 participantes. En cuanto a los resultados alcanzados, se pudo evidenciar que los académicos del área de la salud mostraron mayor apego a los estándares de bioseguridad, mientras que los profesionales necesitan intervenciones orientadas a actualizar este conocimiento. Así, se destacaron las habilidades beneficiosas de la actualización frecuente de la normativa preventiva, reflejando el correcto uso de los EPI, así como la reducción del riesgo de accidentes, siendo la formación en normas de bioseguridad una condición fundamental tanto para los estudiantes como para los profesionales de la salud.

Palabras clave: Bioseguridad; Contagio; Equipo de Protección Individual; Fisioterapia.

\section{Introdução}

O conceito mais usado na literatura para definir Biossegurança foi feito pelos autores Valle; Teixeira (2010), que a definem como um "conjunto de ações voltadas para a prevenção e proteção do trabalhador, minimização de riscos inerentes às atividades de pesquisa, produção, ensino, desenvolvimento tecnológico e prestação de serviços, visando à saúde do homem, dos animais, à preservação do meio ambiente e à qualidade dos resultados”. Assim também, o Ministério da Saúde (2020) definiu a Biossegurança como um conjunto de ações destinadas a prevenir, controlar, mitigar ou eliminar riscos inerentes às atividades que possam interferir ou comprometer a qualidade de vida, a saúde humana e o meio ambiente. Dessa forma, observa-se que a biossegurança é essencial para a pesquisa e para o desenvolvimento sustentável, sendo de suma importância para avaliar e prevenir os possíveis acidentes ou prejuízos à saúde inerentes ao trabalho. As ações de biossegurança em saúde são primordiais para a promoção e manutenção do bem-estar e proteção à vida, não só individual como também coletivo (Sousa et al., 2021a).

A biossegurança no Brasil começou a ser institucionalizada na década de 80 com o Programa de Treinamento Internacional em Biossegurança, ministrado pela Organização Mundial da Saúde (OMS) com o objetivo de estabelecer pontos focais na América Latina para o desenvolvimento do tema. Todavia, apenas em 1995, com a Lei $\mathrm{n}^{\circ} 8.974$ e o Decreto ${ }^{\circ} 1.752$, surgiu a biossegurança, a partir da criação da Comissão Técnica Nacional de Biossegurança (CTNBio), vinculada à Secretaria Executiva do Ministério da Ciência e Tecnologia. Atualmente, é regulamentada pela Lei no 11.105 , de 25 de março de 2005 , que dispõe sobre a Política Nacional de Biossegurança (Teixeira et al., 2020; Sousa et al., 2021b).

Concomitante, a globalização favorece a circulação de agentes químicos, físicos e patogênicos com grande capacidade de propagar-se entre os países. É o que se observa, principalmente, quando novos patógenos surgem, ou novas variantes de um mesmo patógeno como é o caso atual da Covid-19, que obriga a todos a repensarem seus costumes e atos, havendo necessidade de formular políticas e desenvolver estratégias para lidar com áreas específicas, como a biossegurança, a fỉm de conhecer e minimizar os impactos à saúde da população mundial. Sobre isso, destaca-se a utilização de equipamentos de segurança que visam proteger o profissional, pela exposição ou manipulação de agentes com possível risco de contaminação. Eventualmente, são classificados como equipamentos de proteção individual (EPI) e equipamentos de proteção coletiva (EPC), e são 
regulamentados pela Portaria n ${ }^{\circ} 485$, de 11 de novembro de 2005, do Ministério do Trabalho e Emprego, que aprovou a Norma Regulamentadora - NR - 327 (Teixeira et al., 2020).

Desse modo, o EPI constitui instrumento indispensável para a prevenção de agravos. No entanto, a resistência do profissional em utilizá-lo, ou mesmo seu uso incorreto, representam barreiras para prevenir sua exposição. Por tal motivo, é primordial que o trabalhador assuma a responsabilidade de sua segurança e aproprie-se do conhecimento acerca de seu processo de trabalho, bem como dos agravos que têm potencial de ocorrer quando as normas de segurança e medidas de proteção padrão não são adotadas durante suas condutas profissionais (Rocha et al., 2020).

Logo, os segmentos das normas de biossegurança tornam-se ainda mais rigorosos quando se referem aos profissionais de saúde, já que eles estão suscetíveis ao contato com os agentes biológicos, apresentando riscos com as doenças infectocontagiosas, além dos acidentes de trabalho com os instrumentos perfurocortantes (Santos et al., 2017; Teixeira et al., 2020). Nesse contexto, os profissionais da saúde necessitam passar por processos de aprimoramento contínuo. Ademais, a baixa adesão ao uso dos EPI decorre de fatores, como desconforto, descuido, esquecimento e falta de hábito, podendo ser agravada pela precária infraestrutura, aspectos organizacionais do trabalho, falta de conhecimento devido à inexistência de educação permanente, além da sobrecarga de trabalho, estresse, cansaço físico ou ainda pouca percepção dos profissionais acerca dos riscos de seu trabalho (Loro, 2017).

Sendo assim, a abordagem sobre a biossegurança deve ser iniciada durante o período acadêmico, considerando a necessidade da educação continuada, uma vez que as boas práticas seguidas devem ser levadas em consideração durante toda a trajetória profissional (Santos et al., 2017). Com isso, as atividades educativas são cruciais, já que estimulam a construção do pensamento crítico e promovem um repensar da ética e das ciências, tendo como foco a qualificação do indivíduo (Rocha et al., 2020).

Um fator importante que agrega o profissional de saúde à biossegurança é o local de trabalho, sendo os hospitais e ambulatórios regiões de alta complexidade no que se refere aos acidentes, ampliando as chances de contaminação (Júnior et al., 2015). Diante disso, torna-se indispensável entender e seguir os protocolos ideais, evitando os diversos riscos durante contato direto na realização de procedimentos ou na manipulação de instrumentos (Azevedo et al., 2021; Sousa et al., 2021c).

Portanto, o papel das normas de biossegurança está diretamente ligado em intervir e minimizar as consequências dos acidentes, proporcionar maior segurança para esses profissionais, além de evitar os casos de negligência quanto aos procedimentos, tais como higienização das mãos, uso de EPI e adesão às normas universais, garantindo a devida proteção (Marreiro et al., 2019; Pires et al., 2019).

Sendo assim, esta pesquisa justifica-se devido à importância da biossegurança na área da saúde. Para tal, torna-se imprescindível a abordagem para buscar correções fundamentais como forma de intervir na segurança. Além disso, observa-se uma carência de estudos que avaliem a biossegurança na saúde, especificando os âmbitos hospitalares e ambulatoriais.

Tendo em vista o argumento supracitado, o objetivo geral do estudo foi avaliar a aplicabilidade das normas de Biossegurança no âmbito hospitalar e ambulatorial. Os objetivos específicos foram: 1) Analisar os conhecimentos dos avaliados referente às normas de biossegurança; e 2) Apresentar a padronização relacionada às normas de biossegurança.

\section{Metodologia}

\subsection{Delineamento da Pesquisa}

Trata-se de um estudo observacional, transversal e de campo, com abordagem quali-quantitativa, constituído por profissionais e estudantes da área da saúde e executado mediante autorização e assinatura do Termo de Consentimento Livre e Esclarecido de ambos os grupos. 


\subsection{Local da Pesquisa e Caracterização}

A pesquisa foi realizada no Centro de Saúde Ninota Garcia e no Hospital de Urgência de Sergipe Governador João Alves Filho (HUSE). O primeiro local de estudo foi escolhido por corresponder a uma Clínica-Escola da Universidade Tiradentes (UNIT-SE), concentrando diversos estudantes da área da saúde. O segundo ambiente para a realização da pesquisa deu-se por se tratar de um hospital de alta complexidade que abrange grande número de profissionais da saúde. Dessa forma, ambos os locais possuem grande envolvimento com a área da Biossegurança, contendo demanda suficiente de amostras para a execução da pesquisa.

\subsection{Casuística}

A amostra foi realizada por conveniência, sendo recrutados os acadêmicos do $9^{\circ}$ período que participavam do estágio supervisionado obrigatório no Centro de Saúde Ninota Garcia, bem como os profissionais da saúde que estavam em atividades laborais no Hospital de Urgência de Sergipe Governador João Alves Filho (HUSE). A amostra foi constituída por 62 acadêmicos e 52 profissionais, ambos da área da saúde, com os seguintes critérios de inclusão: ter interesse e disponibilidade para preencher o formulário e estar vinculado nos referidos locais para a coleta de dados.

\subsection{Aspectos éticos}

O projeto foi submetido à apreciação ética do Comitê de Ética em Pesquisa (CEP) da Universidade Tiradentes (UNIT). Em seu desenvolvimento, foram observadas as orientações, normas e recomendações éticas para a realização de pesquisas no Brasil, seguindo as determinações expressas na Resolução no 466, de 12 de dezembro de 2012, bem como as resoluções complementares do Conselho Nacional de Saúde do Ministério da Saúde da República Federativa do Brasil. Ao concordarem com a pesquisa, os participantes do estudo assinaram o Termo de Consentimento Livre e Esclarecido (TCLE), tendo a opção de desistirem a qualquer momento.

\subsection{Instrumentos e procedimentos da pesquisa}

Os dados foram coletados através do questionário desenvolvido pelas próprias pesquisadoras, com base em estudos referentes à temática, sendo elaborado como forma de avaliação dos seguimentos às normas de biossegurança por parte dos profissionais da saúde em âmbito hospitalar e dos estudantes em âmbito ambulatorial. O questionário foi elaborado em 15 perguntas de fácil entendimento, impresso e entregue ao entrevistado, a fim de que fosse respondido de acordo com o seu comportamento diante das normas de biossegurança, assinalando a opção com a qual mais se identificasse.

Cada questão apresenta respostas objetivas, variando entre dois e oito itens, com especificidades quanto ao fato de apresentar resposta única ou múltipla resposta, com tempo de preenchimento médio de cinco minutos. A coleta de dados foi realizada mediante questionamento direto a cada profissional da área da saúde recrutado nesse estudo, realizando abordagem no momento da atividade laboral durante a visita técnica. De maneira similar, os estudantes da área da saúde foram abordados no momento do estágio curricular. Em seguida, responderam ao questionário sem interrupção das pesquisadoras, em ambiente reservado e livre de ruídos.

\subsection{Análise estatística}

Inicialmente, os dados coletados foram transportados para uma planilha de dados no programa Excel for Windows 10, em que foi realizada a estatística descritiva e analítica, com as medidas de posição (média), de dispersão (desvio padrão) e frequência absoluta $(\mathrm{N})$ e frequência relativa (\%). Posteriormente, foram feitas análises no programa GraphPad Prisma 6. Para correlação entre as variáveis, foi utilizado o teste de Fisher ou teste de Qui-quadrado. O nível de significância foi fixado em $\mathrm{p}$ 
$<0,05$.

\section{Resultados}

A partir dos dados coletados, o total da amostra foi de 114 participantes, sendo 62 estudantes da Clínica de Saúde Ninota Garcia e 52 profissionais do Hospital de Urgência de Sergipe Governador João Alves Filho (HUSE). Ambos os grupos demonstraram prevalência para o sexo feminino, das quais 70,97\% (44) referem-se ao âmbito ambulatorial e 90,38\% (47) ao âmbito hospitalar. Em relação à idade, a média equivalente ao grupo de estudantes foi de $23,70 \pm 3,83$ anos e do grupo de profissionais da saúde foi de $42,20 \pm 6,35$ anos. No que se refere à formação profissional, houve prevalência dos técnicos de enfermagem, com $34,61 \%$ (TABELA 1).

Tabela 1. Dados gerais dos estudantes e profissionais de saúde entrevistados. Valores apresentados em média \pm desvio padrão, frequência absoluta (n) e relativa (\%).

\begin{tabular}{|c|c|c|}
\hline Dados gerais & Estudantes $(n=62)$ & Profissionais de saúde $(n=52)$ \\
\hline Idade (anos) & $23,70 \pm 3,83$ & $42,20 \pm 6,35$ \\
\hline \multicolumn{3}{|l|}{ Sexo } \\
\hline Feminino & $44(70,97 \%)$ & $47(90,38 \%)$ \\
\hline Masculino & $18(29,03 \%)$ & $5(9,62 \%)$ \\
\hline \multicolumn{3}{|l|}{ Profissão } \\
\hline Assistente social & NA & $1(1,92 \%)$ \\
\hline Aux. de enfermagem & NA & $3(5,77 \%)$ \\
\hline Enfermeiro (a) & NA & $10(19,23 \%)$ \\
\hline Fisioterapeuta & NA & $3(5,77 \%)$ \\
\hline Médico (a) & NA & $8(15,38 \%)$ \\
\hline Nutricionista & NA & $4(7,69 \%)$ \\
\hline Psicólogo & NA & $1(1,92 \%)$ \\
\hline Téc. de enfermagem & NA & $18(34,61 \%)$ \\
\hline Não informado & NA & $4(7,69 \%)$ \\
\hline
\end{tabular}

Legenda: NA: Não avaliado. Fonte: Dados da Pesquisa (2021).

$\mathrm{Na}$ Figura 1, foi apresentado o conhecimento das normas de biossegurança dos participantes da pesquisa, em que apenas $1,61 \%$ (1) dos estudantes identificou não conhecer o conceito e as normas de Biossegurança, ao passo que 7,41\% (4) dos profissionais da saúde demonstraram não ter conhecimento das normas. Em relação à atualização através de curso ou aperfeiçoamento em Biossegurança, nota-se uma distinção ampla entre os discentes e profissionais, identificando uma diferença estatisticamente significativa ( $p<0,0001$ ), visto que $80,64 \%$ (50) dos discentes possuem a devida atualização, enquanto apenas $25,92 \%$ (14) dos profissionais demonstraram ter feito curso ou aperfeiçoamento nesta área nos últimos dez meses. 
Figura 1. Dados sobre biossegurança. Valores apresentados em frequência absoluta (n). Teste de Qui-quadrado, *p <0,05.

\section{Biossegurança}

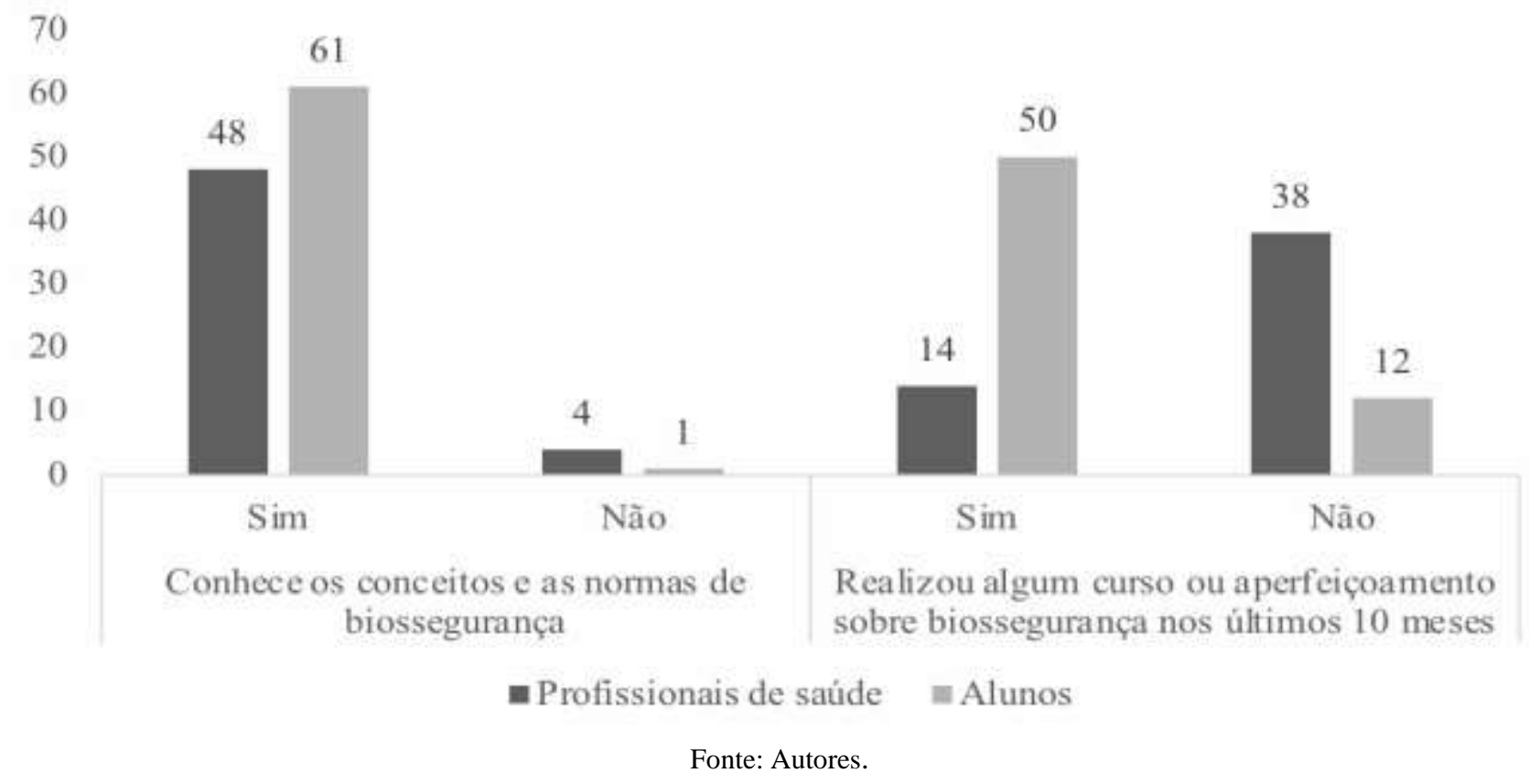

Ao questionar sobre o cartão de vacinação, observou-se que a maioria o mantinha atualizado, em ambos os grupos, com diferença significativa ( $\mathrm{p}=0,034)$ entre eles, em que 88,89\% (48) corresponderam aos profissionais e 74,19\% (46) aos acadêmicos. Sobre os exames preventivos, também foi demonstrada uma diferença considerável, dado que 57,41\% (31) dos profissionais afirmaram realizá-los anualmente e apenas $12,96 \%$ (7) sem regularidade, enquanto $43,55 \%$ (27) dos estudantes cumprem de forma anual e 37,10\% (23) não possuem regularidade, apresentando este último dado diferença estatisticamente significativa $(\mathrm{p}=0,010)$ (Figuras 2 e 3$)$. 
Figura 2. Dados sobre vacinação. Valores apresentados em frequência absoluta (n). Teste de Qui-quadrado, *p <0,05.

\section{Vacinação}

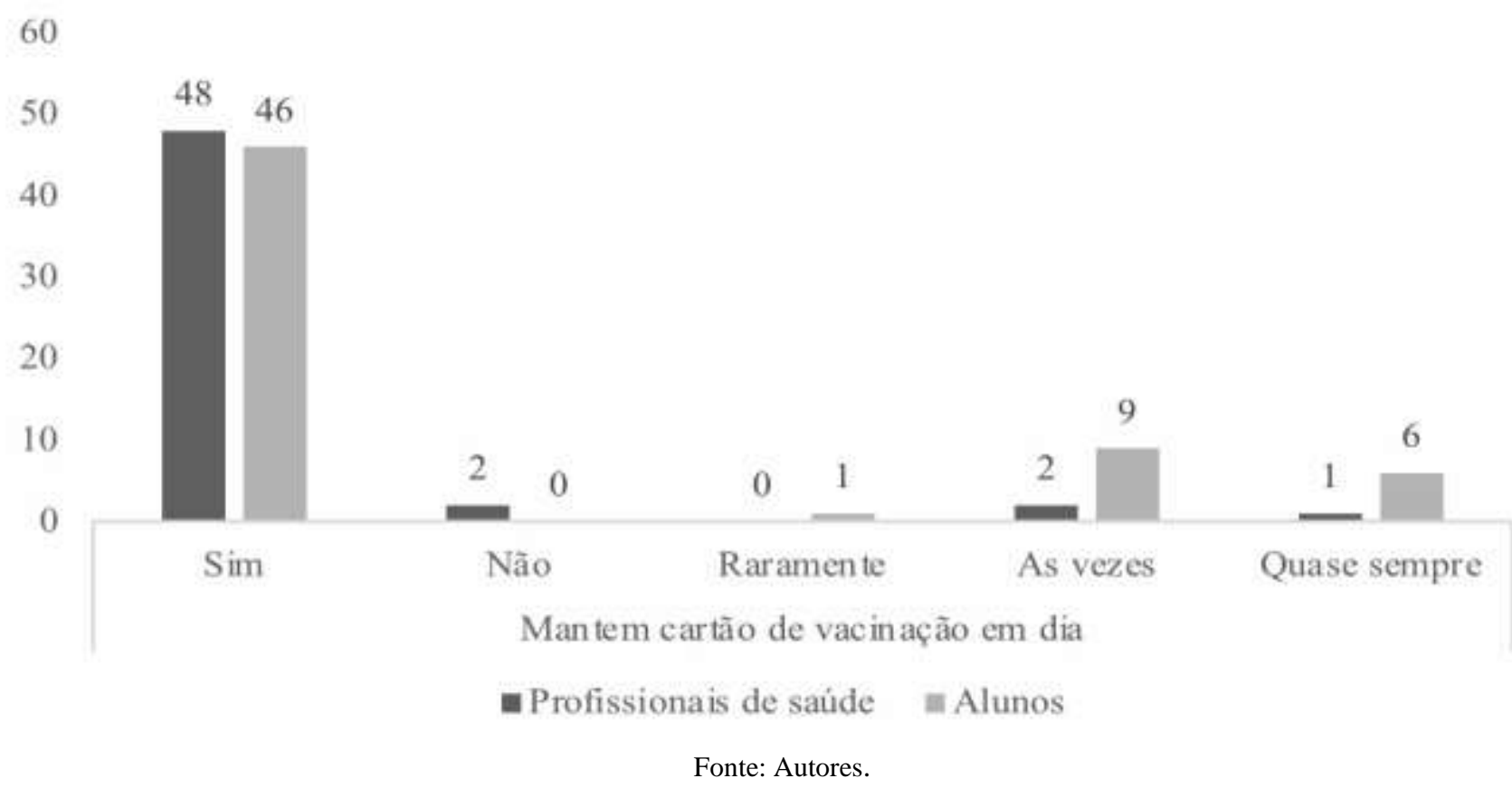

Figura 3. Dados sobre periodicidade dos exames preventivos. Valores apresentados em frequência absoluta (n). Teste de Quiquadrado, $* \mathrm{p}<0,05$.

\section{Exames preventivos}

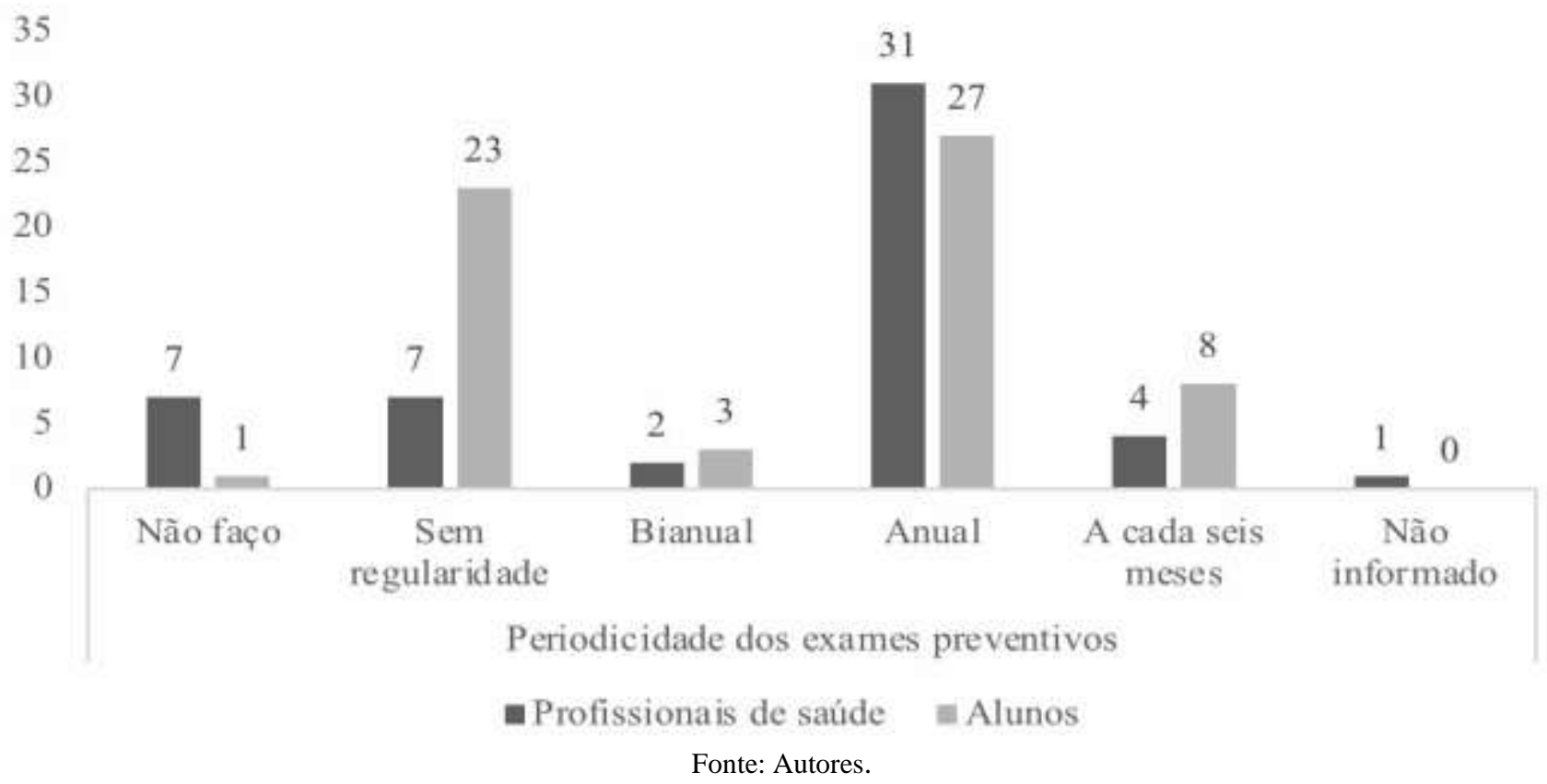

Quanto aos acidentes de trabalho, verificou-se diferença estatisticamente significativa entre os grupos (p < 0,0001), visto que, no âmbito hospitalar, 33,33\% (18) dos indivíduos afirmaram já ter vivenciado algum episódio de acidente de 
trabalho. No entanto, não houve diferença entre os mesmos ao questioná-los sobre a avaliação do risco da situação após um acidente, visto que 68,53\% (37) dos profissionais e 64,52\% (40) dos discentes confirmaram avaliar tais riscos. Por outro lado, sobre a importância de localizar o paciente-fonte após a exposição a material biológico, houve diferença estatisticamente relevante $(p=0,0003)$ entre os profissionais e estudantes, sendo que 85,18\% (46) e 53,22\% (33), respectivamente, identificaram a importância de localizar o paciente-fonte (Figuras 4 e 5).

Figura 4. Dados sobre acidente de trabalho. Valores apresentados em frequência absoluta (n). Teste de Qui-quadrado, *p $<0,05$.

\section{Acidente de trabalho}

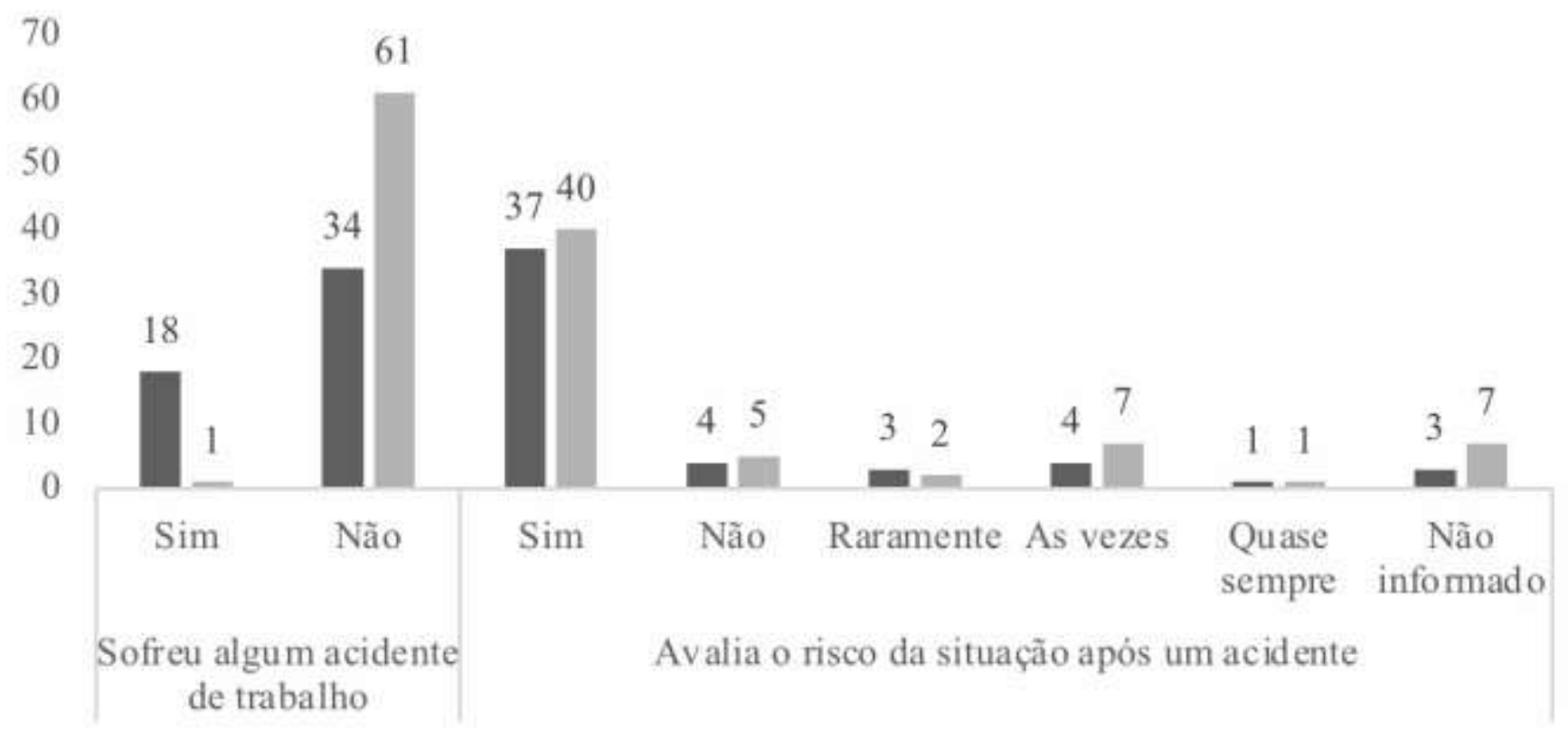

Profissionais de saúde $=$ Alunos

Fonte: Autores. 
Figura 5. Dados sobre a importância da identificação do paciente-fonte. Valores apresentados em frequência absoluta (n). Teste de Qui-quadrado, ${ }^{*} \mathrm{p}<0,05$.

\section{Identificação do paciente-fonte}

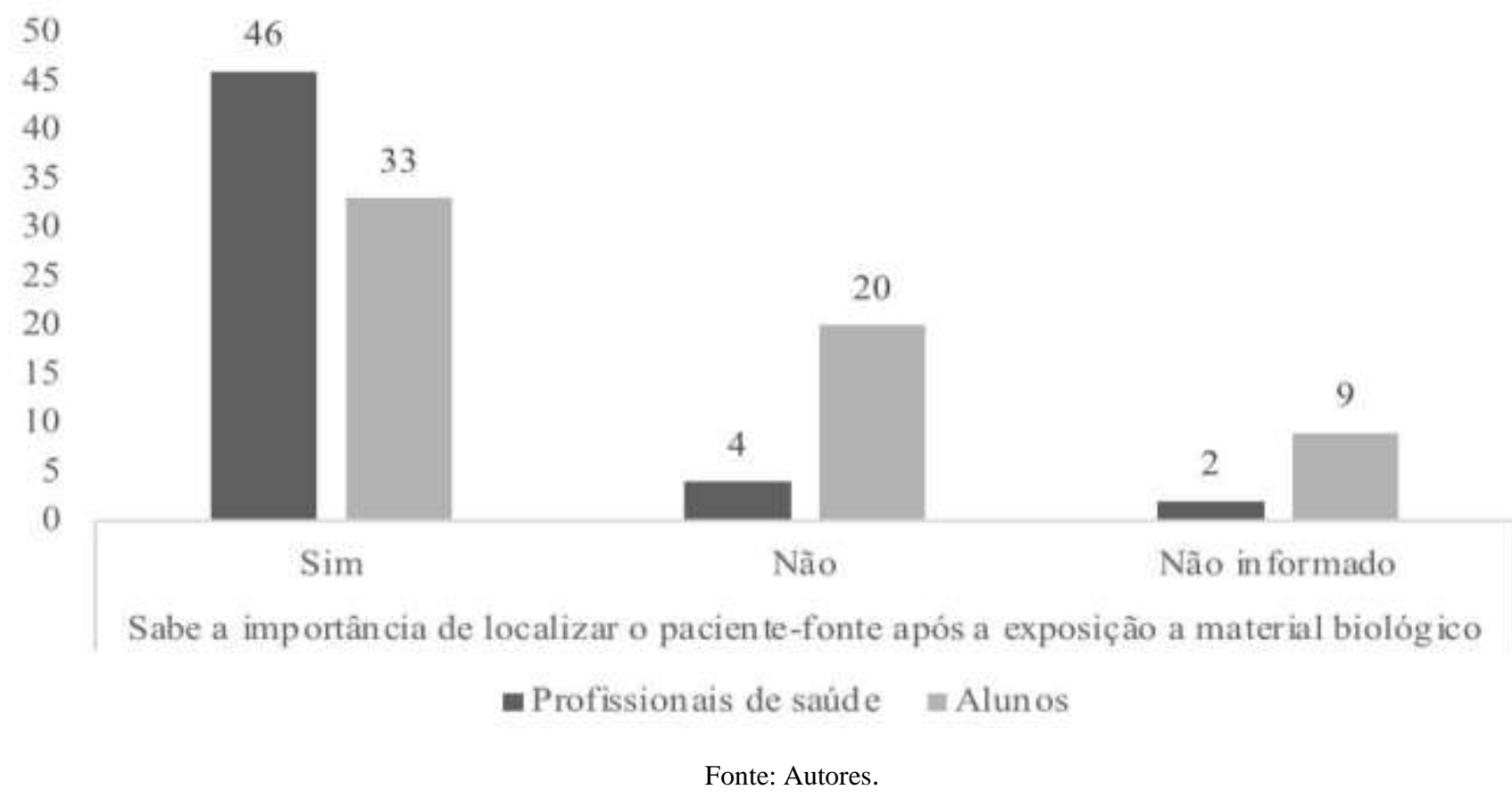

Ao analisar os fatores que contribuem para os acidentes de trabalho, foram notadas algumas condições que favorecem tais ocorrências, como o ritmo de trabalho intenso, com prevalência de 64,81\% (35) dos profissionais da saúde e 58,06\% (36) dos estudantes, além da sobrecarga de trabalho relatada pelos profissionais, com 81,48\% (44), e pelos estudantes, com 79,03\% (49). Outro fator refere-se à falta de treinamento, sendo observada tanto nos profissionais, com 46,30\% (25), quanto nos estudantes, com $82,26 \%$ (51). Por fim, deve-se considerar a falta de equipamentos individuais e coletivos, relatada por $35,18 \%$ (18) dos profissionais e por 66,13\% (41) dos estudantes (Figura 6). 
Figura 6. Dados sobre fatores que contribuem para a ocorrência de acidentes laborais. Valores apresentados em frequência absoluta (n). Teste Qui-quadrado, *p $<0,05$.

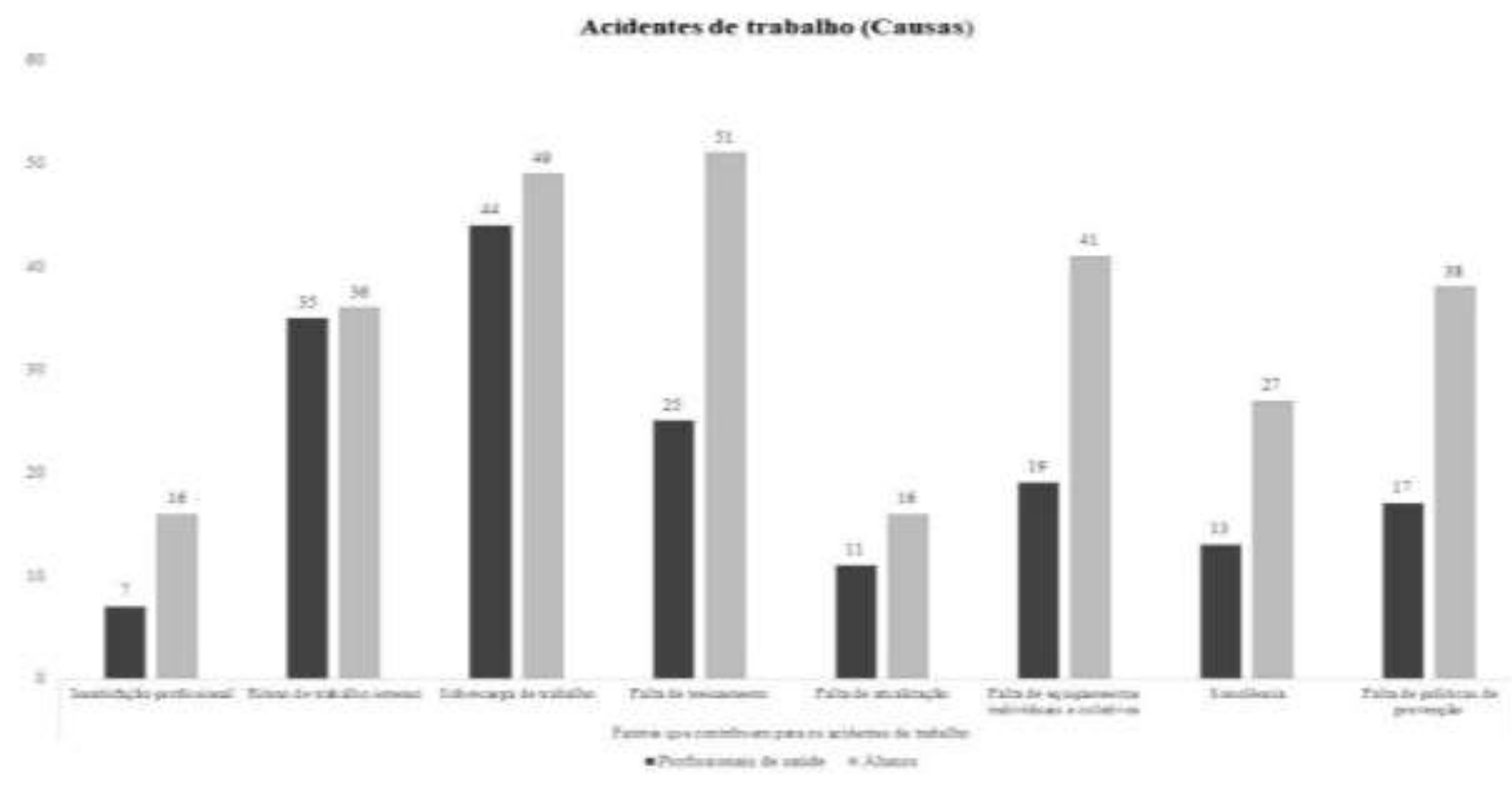

Fonte: Autores.

Em relação ao EPI, ressalta-se que a utilização de óculos de proteção, máscaras e gorros foi prevalente nos estudantes, com 90,32\% (56), enquanto 57,41\% (31) dos profissionais fazem uso de tais paramentações, com diferença estatisticamente significativa $(\mathrm{p}=0,002)$ entre os grupos. Considerando a exposição a fluidos corporais, ambos os grupos dispõem de máscaras e luvas durante a realização das condutas, perfazendo 96,77\% (60) dos estudantes e 88,89\% (48) dos profissionais (FIGURAS 7 e 8).

Figura 7. Dados sobre o uso de EPIs. Valores apresentados em frequência absoluta (n). Teste de Qui-quadrado, *p $<0,05$.

\section{Uso de óculos de proteção, máscara e gorro}

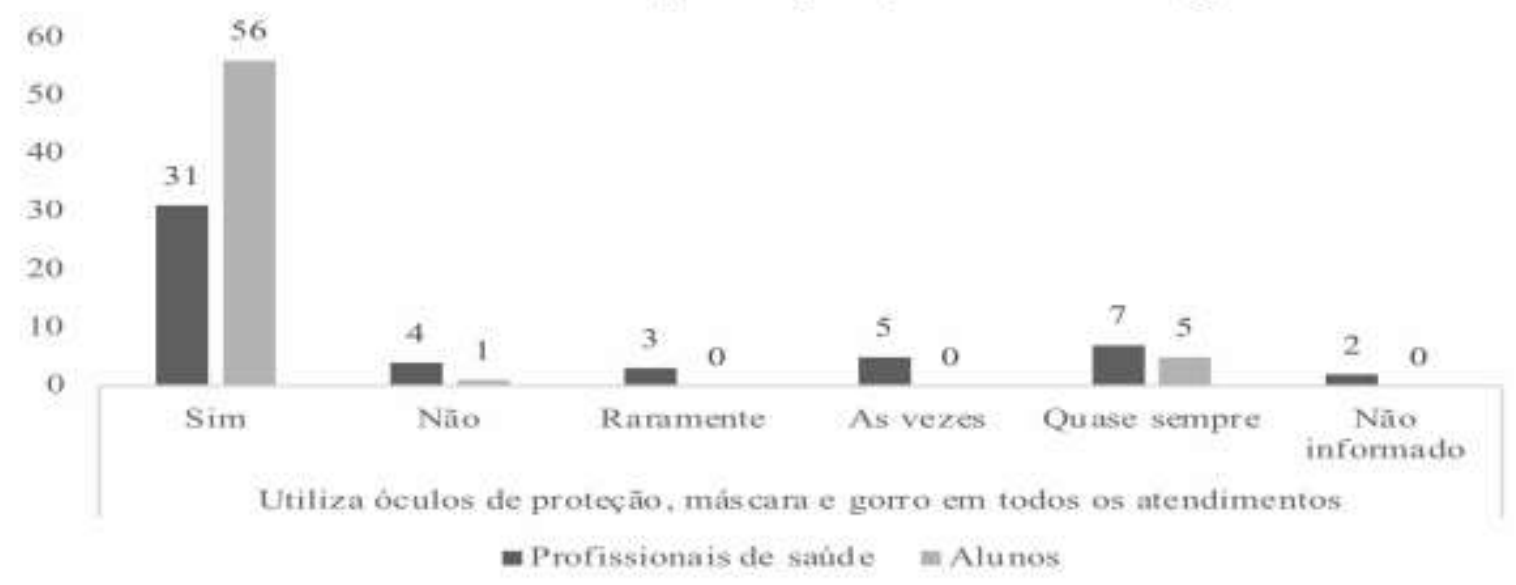

Fonte: Autores. 
Figura 8. Dados sobre o uso de EPIs em condutas que apresentem risco de contágio. Valores apresentados em frequência absoluta (n). Teste de Qui-quadrado, *p <0,05.

\section{Uso de EPIs em condutas que apresentem risco de contágio}

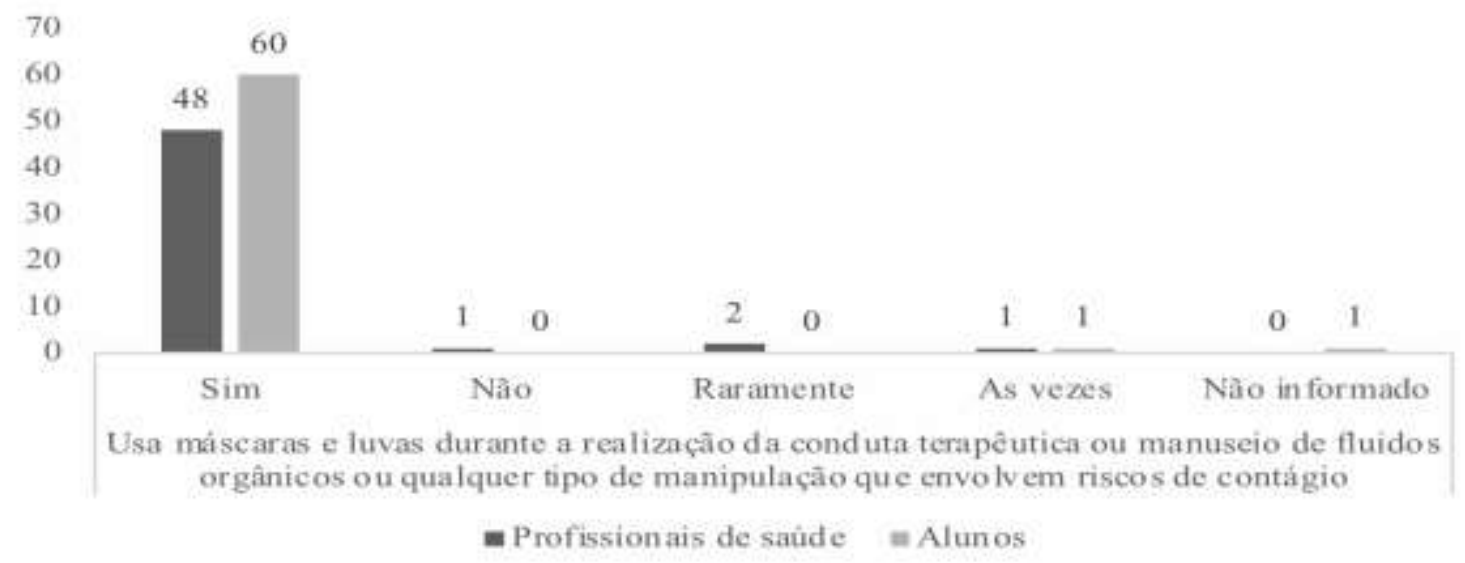

Fonte: Autores.

Mediante os resultados apresentados nas Figuras 9 e 10, nota-se que ambos os grupos realizam o descarte de luva após cada procedimento, representando 94,44\% (51) e 98,39\% (61), respectivamente. Ao interrogá-los sobre a lavagem das mãos após contato direto com o paciente, percebeu-se diferença estatisticamente significativa ( $\mathrm{p}=0,014)$ entre os grupos, com $92,59 \%$ (50) dos profissionais e 74,19\% (46) dos acadêmicos.

Figura 9. Dados sobre o descarte de luvas após cada procedimento. Valores apresentados em frequência absoluta (n). Teste de Qui-quadrado, *p <0,05.

\section{Descarte das luvas após procedimento}

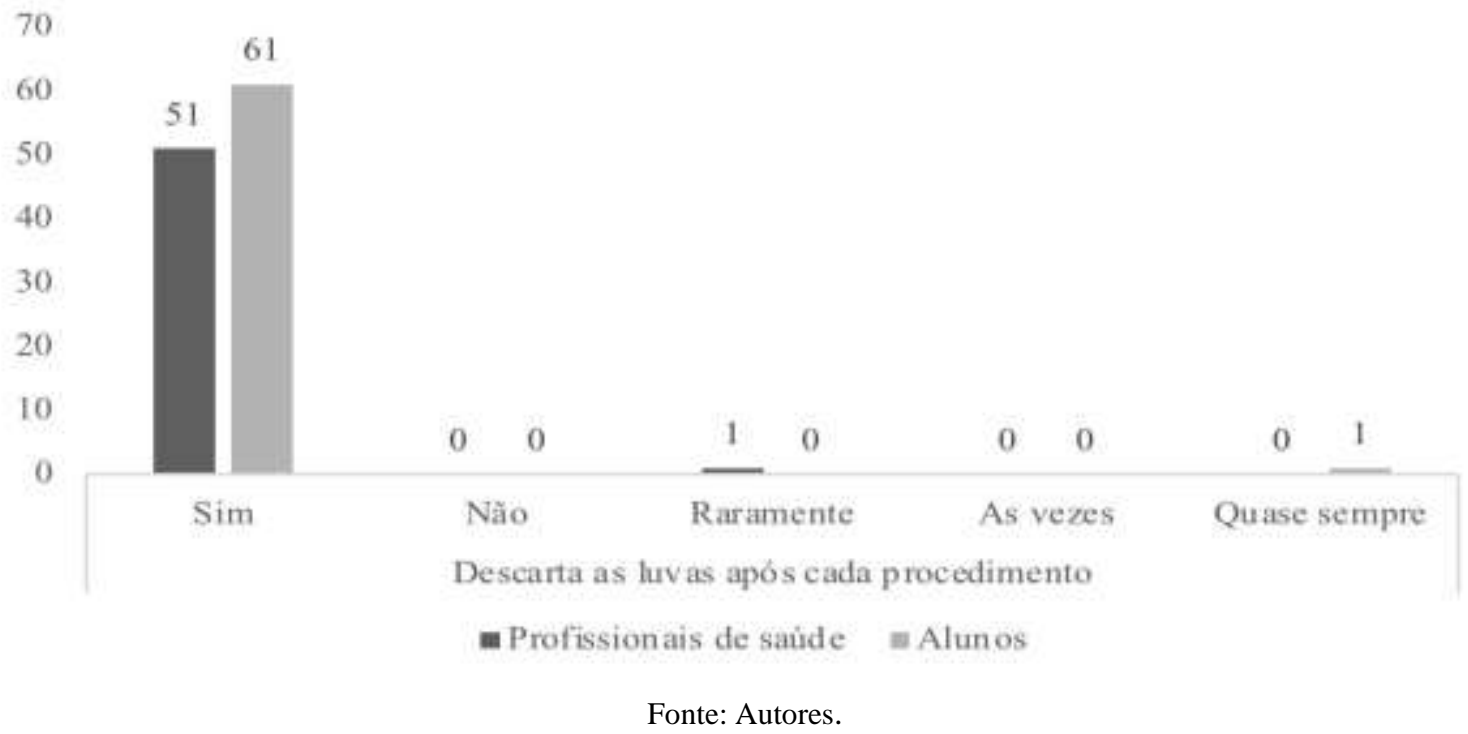


Figura 10. Dados sobre lavagem das mãos após o contato direto com cada paciente. Valores apresentados em frequência absoluta (n). Teste de Qui-quadrado, *p <0,05.

\section{Lavagem das mãos após contato direto com paciente}

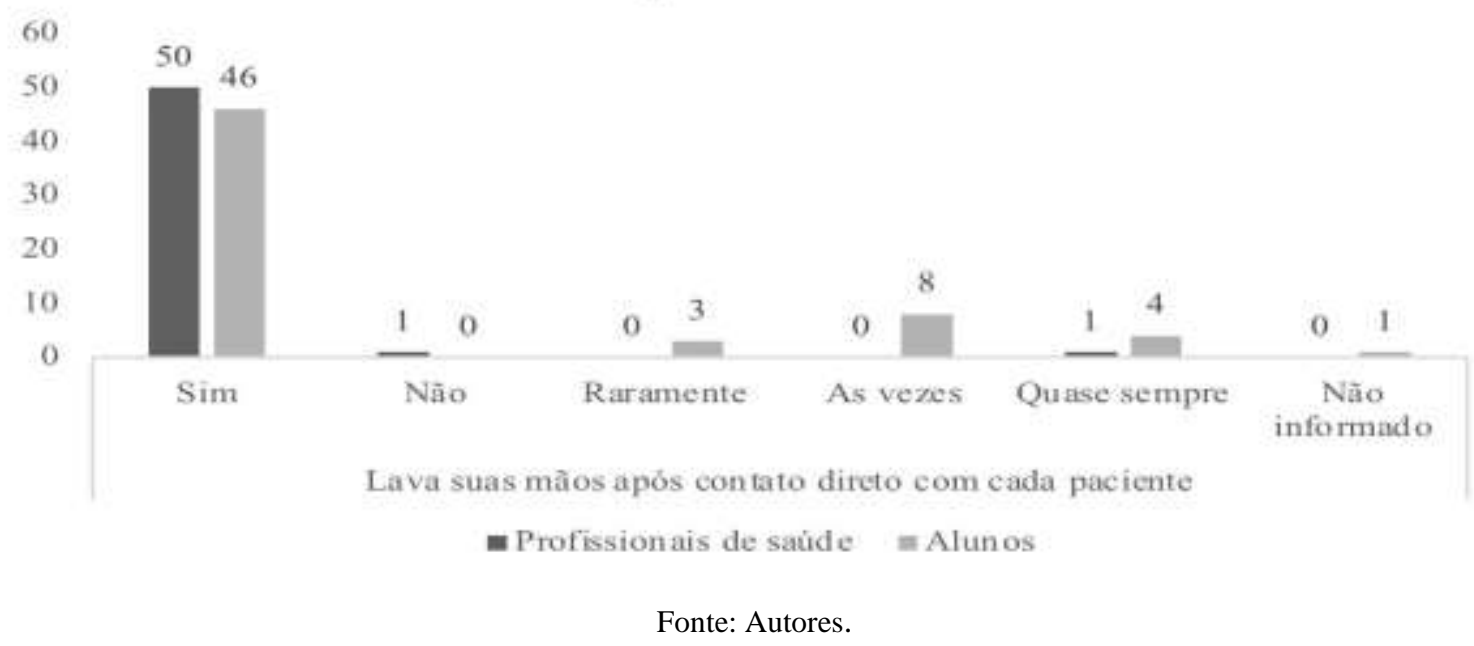

De acordo com as Figuras 11 e 12, afirma-se que ambos os grupos possuem conhecimento quanto ao compartilhamento de materiais hospitalares, já que 42,59\% (23) dos profissionais e 53,22\% (33) dos alunos demonstraram não realizar tal compartilhamento. No que diz respeito à higienização dos materiais utilizados nos pacientes, observa-se que 40,74\% (22) dos profissionais os higienizam antes da sessão, enquanto 44,44\% (24) ao final do atendimento. Em se tratando dos discentes, 43,55\% (27) realizam a higienização antes da sessão, ao passo que 37,10\% (23) assim o fazem ao final do atendimento.

Figura 11. Dados sobre a higienização dos materiais. Valores apresentados em frequência absoluta (n). Teste de Quiquadrado, $* \mathrm{p}<0,05$.

\section{Higienização dos materiais}

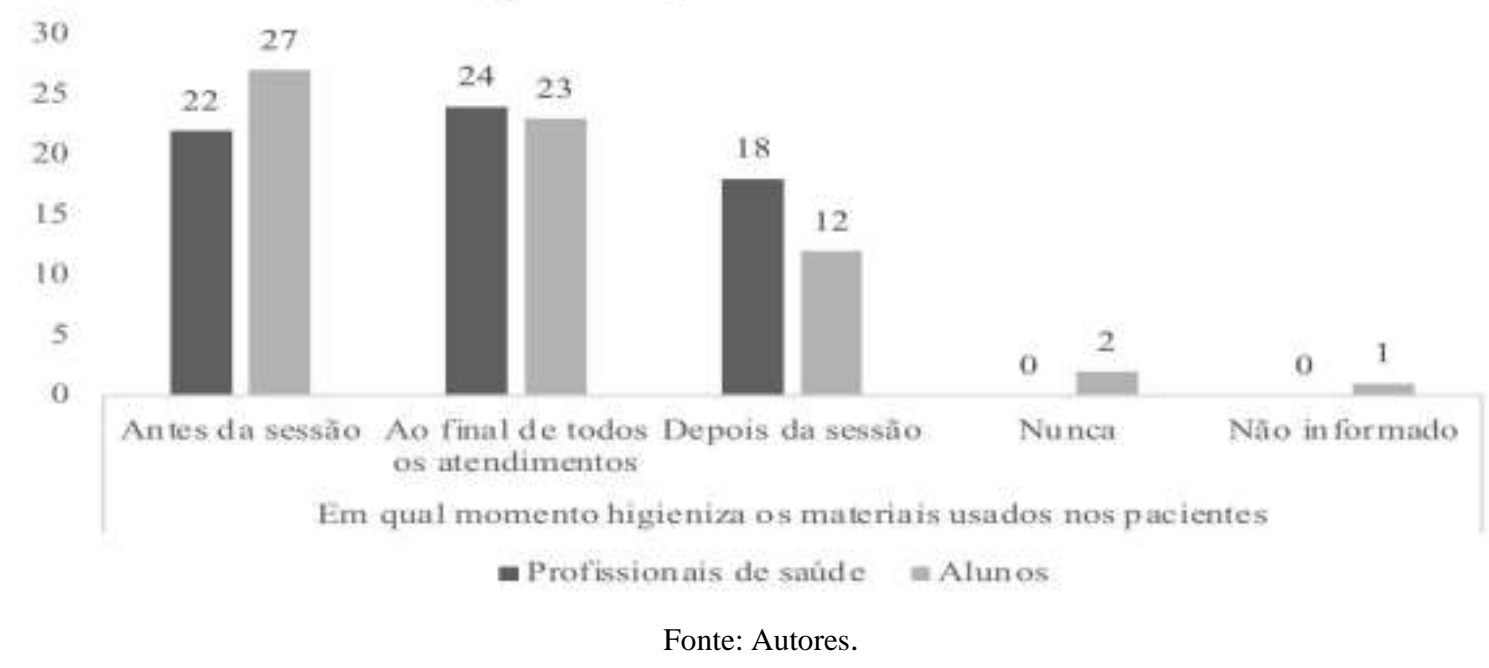


Figura 12. Dados sobre o compartilhamento de materiais. Valores apresentados em frequência absoluta (n). Teste de Quiquadrado, $* \mathrm{p}<0,05$.

\section{Compartilhamento de materiais}

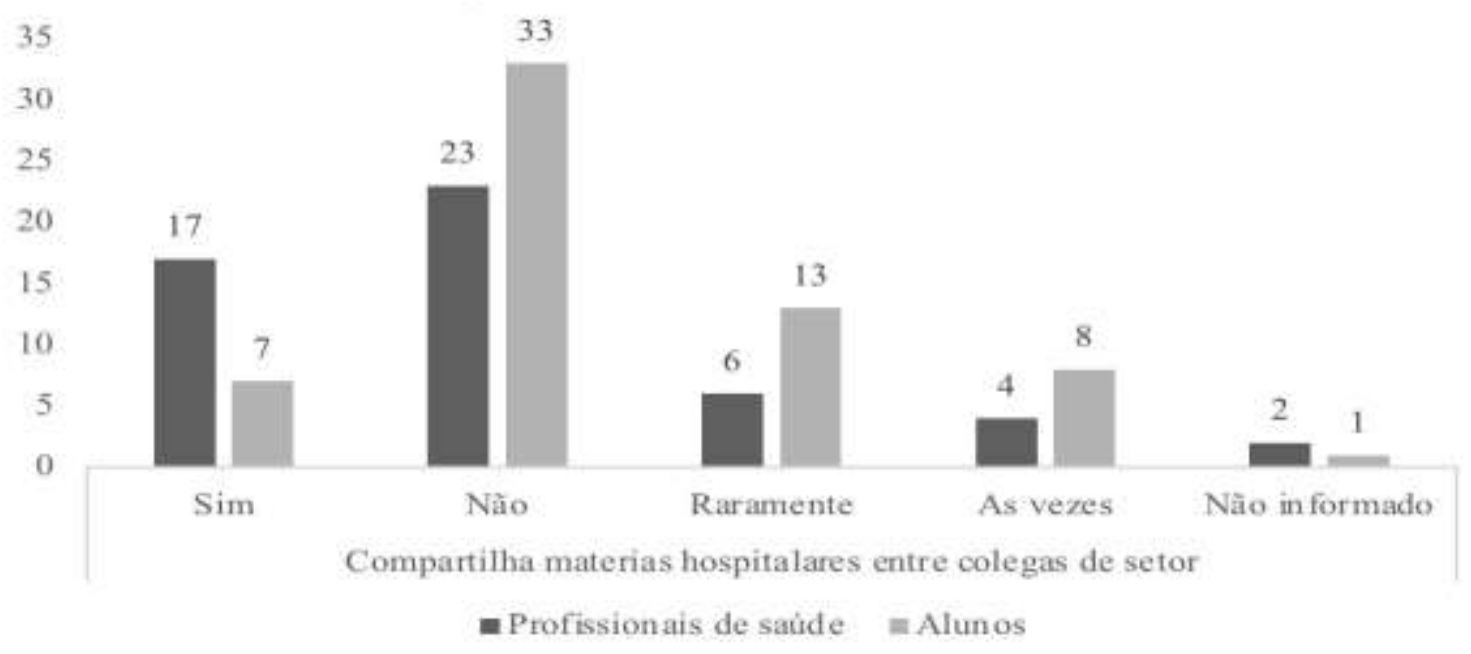

Fonte: Autores.

\section{Discussão}

De acordo com o estudo sobre medidas de Biossegurança realizado por Bermúdez et al. (2021), em sua amostra, houve prevalência do sexo feminino correspondente a $82 \%$ entre os profissionais da área da saúde quando comparado ao sexo masculino. Languré et al. (2016) apresentaram resultados coincidentes, em que dos 45 profissionais que compuseram a pesquisa, $73 \%$ representaram as mulheres e apenas $27 \%$ foram homens. Na pesquisa de Santos et al. (2021), notou-se predomínio de estudantes do sexo feminino $(75,2 \%)$ quando comparado ao sexo masculino $(24,8 \%)$.

No presente estudo, o número total da amostra foi de 114 participantes referentes à área da saúde, sendo 62 estudantes e 52 profissionais. Ambos os grupos também demonstraram preponderância para o sexo feminino, em que 70,97\% (44) referem-se aos estudantes e 90,38\% (47) aos profissionais, corroborando os estudos supracitados.

Em relação à idade, Cordeiro (2016), em seu estudo, identificou uma média de idade de 47,8 anos entre os profissionais da saúde. Similarmente, Lima et al. (2017) mostraram que a faixa etária predominante entre os profissionais da saúde foi de 40 a 49 anos. No estudo de Passos et al. (2020), constatou-se que a média de idade entre os profissionais participantes da pesquisa foi 40,4 anos (com variação entre 24,9 a 65,9 anos). De forma semelhante, no presente estudo, notouse que entre os profissionais da saúde a média de idade foi de 42,20 $\pm 6,35$ anos. Por outro lado, Morais et al. (2017) encontraram resultados divergentes com os autores acima, detectando uma faixa etária mais elevada, com prevalência de $34,4 \%$ naqueles com 58 a 68 anos.

O estudo de Santos et al. (2021), realizado com 105 discentes da área da saúde, identificou uma média de idade de participantes equivalente a 22,6 anos, o que condiz com o atual estudo, no qual foi observado que entre os estudantes a média de idade foi correspondente a $23,70 \pm 3,83$ anos.

Segundo Cabral et al. (2013), torna-se importante analisar as principais medidas de biossegurança a serem adotadas em hospitais para prevenir ou controlar as infecções e caracterizar os principais fatores que induzem os profissionais da área da saúde aos riscos ambientais.

Bermúdez et al. (2021), ao avaliarem o conhecimento das normas de Biossegurança dos profissionais pesquisados, notaram que $83 \%$ possuem amplo entendimento sobre o assunto. Tais resultados assemelham-se aos de Moraes et al. (2017), 
em que 100\% da amostra afirmou conhecer o significado de Biossegurança. Da mesma forma, o atual estudo identificou que 88,89\% dos profissionais e 98,39\% dos estudantes possuem o conhecimento do conceito e normas de Biossegurança, identificando que, neste quesito, os estudantes possuem mais domínio sobre o assunto do que os profissionais avaliados.

No entanto, no estudo de Islam et al. (2020), foi possível observar uma divergência aos resultados supracitados, em que apenas $6 \%$ dos entrevistados relataram compreender o conceito de Biossegurança. De maneira semelhante, Languré et al. (2016) demonstraram em seu estudo que $69 \%$ dos profissionais desconhecem as normas de prevenção de riscos ocupacionais.

Para Passos e Marziale (2020), em sua amostra constituída por 165 profissionais da saúde, 98,2\% dos participantes identificaram conhecer as medidas de precauções-padrão, porém alguns conceitos apresentavam-se errôneos e até equivocados, como a higienização das mãos durante a prestação de cuidados a pacientes diferentes e a necessidade do uso de óculos e gorros. Todavia, apesar de os profissionais demonstrarem conhecer as normas, muitos trabalhadores necessitam de atualização. Tais treinamentos são indicadores de redução do risco de exposição e favorecem o aumento da adesão às normas.

De acordo com o estudo de Cabral et al. (2013), o risco de transmissão de infecção para o trabalhador da área de saúde depende da hierarquização e complexidade da atividade que desenvolve, do tipo de atendimento prestado às pessoas e da função que desempenha. Ademais, existem condições no ambiente de trabalho capazes de provocar danos à saúde ou à integridade física do trabalhador, que são os riscos ocupacionais, os quais variam e dependem também de problemas administrativos, financeiros, treinamento, educação continuada, normas e rotinas, existência de EPI, EPC e outros.

Lima et al. (2017) ressaltam a importância do treinamento voltado para biossegurança, visto que intervém positivamente na tomada de decisão quanto à utilização de medidas de precaução. Islam et al. (2020) sugerem a realização de projetos que levam em consideração o treinamento de biossegurança através de palestras, seminários e reuniões para revisão de diretrizes de segurança institucionais, visando abordar as lacunas identificadas no estudo. Tais aspectos condizem com o estudo de Ma et al. (2020), o qual aborda a importância de incentivar os profissionais da saúde a obterem conhecimento e habilidades quanto à proteção através da biossegurança.

Para Cabral et al. (2013), a biossegurança pode evitar e prevenir a infecção dos trabalhadores da área de saúde, porém, para que isso ocorra, faz-se necessário o treinamento efetivo, a utilização dos equipamentos de proteção, os cuidados preventivos individuais e o seguimento às normas e procedimentos vigentes, com intuito estabelecer uma organização para garantir a segurança.

No que se refere aos achados do estudo atual, apenas 25,92\% dos profissionais realizaram algum curso ou aperfeiçoamento sobre Biossegurança nos últimos dez meses. Esse dado difere dos resultados de Ferreira et al. (2017), em que $72,2 \%$ dos profissionais do âmbito hospitalar identificaram no questionário ter recebido algum treinamento sobre adesão às medidas de prevenção padrão na instituição nos últimos seis meses. A mesma prevalência foi observada no estudo de Morais et al. (2017), visto que $77,1 \%$ dos profissionais integrantes da pesquisa já participaram de curso ou palestra sobre a temática. Entretanto, ao avaliar os resultados dos estudantes, nota-se que $84,64 \%$ realizaram cursos ou aperfeiçoamentos nos últimos dez meses, salientando uma contraposição aos profissionais.

Segundo Morais et al. (2017), outra condição importante para a proteção e prevenção dos profissionais da saúde é a imunização, posto que corresponde a mais uma medida de proteção contra as doenças imunopreveníveis. Quanto a esse assunto, os avaliados do atual estudo foram questionados sobre a atualização do cartão de vacina, sendo observado que $88,89 \%$ dos profissionais e 74, 19\% dos estudantes da saúde mantêm suas vacinas em dia. Languré et al. (2016) evidenciaram a influência da equipe administrativa das unidades de saúde para que sejam estabelecidas políticas e protocolos de vacinação para imunizar toda a equipe de saúde presente tanto no ambiente hospitalar quanto no ambulatorial.

Cabral et al. (2013) ratificaram que o profissional de saúde deve adotar medidas com a finalidade de reprimir o risco de infecção, utilizando procedimentos simples, como a realização de exames preventivos que possam detectar possíveis 
doenças. Dessa forma, o risco do ataque de outras possíveis infecções hospitalares será reduzido ou eliminado. O atual estudo mostrou que $57,41 \%$ dos profissionais e $43,55 \%$ dos estudantes identificaram realizá-los de forma anual.

Islam et al. (2020), em seu estudo, avaliaram a presença de acidentes de trabalho no determinado setor de um hospital público e relataram não haver registro de acidentes, mantendo relação com os dados obtidos no presente estudo no grupo de estudantes, no qual apenas $1,61 \%$ relatou ter presenciado algum acidente. Tais achados vão de encontro aos resultados de Morais et al. (2017), uma vez que foi possível constatar que 22,9\% dos profissionais já sofreram acidentes de trabalho com materiais biológicos. O estudo atual é consistente com os dados citados, já que 33,33\% dos profissionais relataram vivenciar algum acidente de trabalho.

Conforme Cabral et al. (2013) destacam em seu estudo, a avaliação do risco após o acidente visa classificar a patogenicidade do agente infeccioso e seus possíveis danos, bem como eliminá-los ou minimizar seus efeitos. Dessa forma, torna-se necessário adotar uma metodologia estruturada e sistemática com o intuito de gerenciar tais riscos através de medidas preventivas. Em conformidade, o atual estudo evidencia que 68,53\% dos profissionais e 64,52\% dos discentes avaliam os riscos da situação após um acidente.

Na pesquisa realizada por Ishaque et al. (2021), ao analisarem a gestão de acidentes, constatou-se a importância de localizar o paciente-fonte, a fim de encaminhá-lo para o atendimento médico instantâneo, visando ao cuidado inicial, à busca do controle da infecção, bem como estabelecendo os fatores de risco provenientes de possíveis acidentes. Isto posto, o atual estudo identificou, mediante seus resultados, que grande parte dos profissionais $(85,18 \%)$ possuem mais cautela quanto à localização do paciente-fonte após exposição aos materiais biológicos, em comparação aos estudantes, visto que 53,22\% dos mesmos relataram efetuar tal cuidado.

De acordo com Cabral et al. (2013), há necessidade de comunicar a ocorrência de acidente de trabalho por parte dos profissionais de saúde no setor responsável, visto que estes estão mais expostos aos riscos ocupacionais, incluindo o contato das membranas mucosas, pele não íntegra, acidentes percutâneos, ao sangue, fluidos orgânicos (secreção e excreção), potencialmente transmissores do Human immunodeficiency virus (HIV), Hepatitis B Virus (HBV) e Hepatitis C Virus (HCV). Dessa maneira, tornam-se necessárias medidas precoces para o tratamento da lesão, além de sanar as dúvidas do profissional. Entretanto, são poucos os serviços que possuem estrutura para atender e notificar os casos de acidentes, o que dificulta a análise sobre a prevalência de acidentes de trabalho envolvendo esses profissionais no ambiente hospitalar. Além disso, os profissionais deparam-se com barreiras institucionais, pressões econômicas e técnicas para que as medidas de biossegurança sejam implantadas.

Lima et al. (2017), ao avaliarem 67 profissionais, puderam observar o predomínio de alguns fatores que predispõem a acidentes de trabalho, sendo eles: indisponibilidade das medidas de proteção, uso irregular dos equipamentos de proteção individual e coletiva, supervisão ineficiente e não observação de normas e práticas inadequadas. Costas et al. (2020) apresentaram achados coincidentes, uma vez que também consideram o excesso de trabalho, o estresse, a falta de equipamentos e até mesmo a estrutura física do ambiente como fatores cruciais para possíveis acidentes de trabalho. Tais circunstâncias mantêm relação com o estudo de Ferreira et al. (2017), ao afirmar que a sobrecarga de trabalho é uma condição facilitadora para a ocorrência de falhas.

Os profissionais e discentes da área da saúde avaliados no presente estudo concordaram, por intermédio do questionário aplicado, que o ritmo de trabalho intenso, a sobrecarga, a falta de treinamento, somados à falta de equipamentos de segurança tanto individuais quanto coletivos são importantes para colocar a saúde deles em risco durante sua jornada de trabalho.

Passos e Marziale (2020) corroboram o estudo atual no que se refere aos diversos fatores predisponentes a acidentes, uma vez que a literatura identifica a baixa adesão interligada ao desconforto e incômodo sentidos pelos profissionais, além do 
descuido, esquecimento, falta de hábito, inadequação dos equipamentos e escassez de materiais. Ademais, identifica-se que a baixa adesão por parte dos participantes em relação à utilização de óculos de proteção ocorre devido à dificuldade de visualização, bem como à presença de dúvidas sobre quando eles devem ser utilizados. A experiência profissional é citada no estudo de Cordeiro (2016) como um fator aliado à utilização correta dos EPI's, podendo minimizar a exposição aos riscos biológicos. Por outro lado, o mesmo estudo evidenciou que o despreparo do profissional é expresso pelo desconhecimento do uso correto das precauções-padrão.

Adicionalmente, Silva et al. (2021), em seu estudo, revelaram que a principal maneira de transmissão de agentes infecciosos é a quebra da barreira de proteção, de modo que a utilização correta de máscaras, gorros, luvas, óculos de proteção ou protetor facial protege os profissionais da saúde. Segundo Ma et al. (2020), os EPI's são ferramentas essenciais para a rotina tanto dos profissionais quanto dos estudantes da área da saúde, sendo necessário investir em planos educativos nas universidades, clínicas-escolas e hospitais, tendo em vista os conhecimentos acerca da biossegurança, além de alertá-los quanto aos riscos relacionados ao seu descumprimento.

Gerenciar os riscos de acidentes no âmbito hospitalar é fundamental, assim como adotar uma metodologia estruturada e sistematizada para identificação e avaliação de tais riscos, conforme exposto no artigo de Cabral (2013), visto que reforça a importância de controlar os riscos através dos seguintes meios, sendo eles o uso de equipamento de proteção coletiva, equipamentos de proteção individual, imunização e aplicação de forma planejada das ferramentas para avaliação e correção do sistema de biossegurança.

No presente estudo, foi ressaltado que a utilização dos EPI's acerca de óculos de proteção, máscaras e gorros foi prevalente nos estudantes, com $90,32 \%$, enquanto $57,41 \%$ dos profissionais afirmaram fazer uso de tais paramentações. Ferreira et al. (2017) apontam que, conforme o profissional adquire experiência, é conquistada mais confiança e habilidade prática, tornando-o menos propenso a aderir às medidas de proteção.

De igual forma, Morais et al. (2017) observaram que 85,7\% dos acadêmicos afirmaram utilizar EPI para a realização de seus atendimentos, ambos os estudos contrariando os resultados do presente estudo. No entanto, Santos et al. (2021) contrariam os dados obtidos pelos estudantes da atual pesquisa, uma vez que os resultados demonstram que a maioria dos discentes não identificaram o uso de máscaras como uma medida de precaução-padrão.

Segundo o estudo de Bermúdez et al. (2021), a utilização de máscaras e luvas durante a realização de conduta terapêutica que envolve risco de contágio previne significativamente as infecções e o risco tanto para os pacientes que se encontram em ambiente insalubre, quanto para os profissionais. Todavia, seus resultados mostram que o número de profissionais que se paramentam adequadamente é baixo, visto que apenas 33,33\% deles costumam utilizar máscaras e luvas para realizarem procedimentos invasivos. De forma similar, Languré et al. (2016), ao avaliarem 88 profissionais da saúde, observaram que apenas $31 \%$ utilizam os equipamentos de barreira.

Conquanto, de maneira contraditória aos dados supracitados, o estudo atual mostrou que 96,77\% dos estudantes e 88,89\% dos profissionais apontaram dispor de máscara e luva durante qualquer tipo de manipulação que envolve risco de contágio, demonstrando que grande parte dos profissionais utilizam barreira de proteção adequada.

Cabral et al. (2013) apontaram em seu estudo a necessidade de descarte de materiais perfurocortantes em recipientes apropriados com resistência elevada à perfuração e com fechamento de forma adequada, havendo redução de propagação de doenças dentro do ambiente hospitalar, bem como prevenção de infecções nos profissionais. Mediante os resultados apresentados neste estudo, notou-se que tanto o grupo hospitalar quanto o ambulatorial realizam o mecanismo de descarte de luva após cada procedimento, representando $94,44 \%$ e $98,39 \%$, respectivamente.

Vasconcelos et al. (2018) evidenciaram que a lavagem das mãos constitui a prática mais eficaz e econômica de evitar contaminação cruzada. Segundo os estudos de Chavarria et al. (2018), o risco biológico está vinculado às práticas de lavagem 
das mãos e, dessa maneira, se o conhecimento sobre risco biológico é nível médio/alto, as práticas de lavagem das mãos serão consideradas ótimas. Por outro lado, se o nível de conhecimento é baixo, as práticas de lavagem das mãos também serão. Os autores Passos; Marziale (2020) garantem que todos os profissionais devem realizar a higienização das mãos antes e após a prestação de cuidado a cada paciente, mesmo quando são utilizadas luvas de procedimento e manipulados materiais biológicos, tanto para a segurança do paciente, quanto para a do profissional, uma vez que a inadequada higienização das mãos pelos profissionais de saúde entre o atendimento de pacientes é comprovadamente uma fonte de contaminação.

Não obstante, Bermudéz et al. (2021), em estudo conduzido por 90 profissionais da saúde, evidenciaram que apenas 28\% dos participantes realizaram a lavagem das mãos após contato direto. De forma contrária, no estudo de Passos; Marziale (2020), foi possível identificar que $84,1 \%$ dos participantes declararam realizar a higienização das mãos entre a prestação de cuidados a pacientes diferentes, $89 \%$ responderam higienizar as mãos após retirar as luvas e 96,3\% após contato com material biológico.

Em concordância ao estudo de Passos e Marziale (2020), o presente estudo identificou que 92,59\% dos profissionais e $74,19 \%$ dos estudantes seguem os procedimentos adequados de lavagem das mãos após contato direto com cada paciente.

Ishaque et al. (2021) também salientaram que os dispositivos de saúde utilizados pelos profissionais representam outra condição de transmissibilidade por contato indireto, incluindo termômetros de monitoramento de temperatura, glicosímetros, esfigmomanômetro, dentre outros. Posto isso, o atual estudo identificou que ambos os grupos da pesquisa possuem o devido conhecimento quanto ao compartilhamento de materiais hospitalares, visto que $42,59 \%$ dos profissionais e $53,22 \%$ dos acadêmicos demonstraram não realizar tal compartilhamento.

De acordo com Pimentel et al. (2015), os dispositivos de saúde devem ser devidamente higienizados e esterilizados com álcool antes e após os atendimentos, com o intuito de garantir a limpeza correta e evitar o transporte e a transmissão de patógenos. O atual estudo demonstra divergência ao afirmar que apenas $40,74 \%$ dos profissionais e $43,55 \%$ dos discentes higienizam os materiais antes de sua utilização.

Santos et al. (2021) evidenciaram que, durante a utilização dos devidos EPI's, torna-se fundamental que os profissionais e acadêmicos da saúde removam acessórios, sendo eles relógios, pulseiras, anéis, bem como disponham de cuidados com as unhas, as quais devem ser curtas, a fim de evitar contaminações e minimizar o risco de lesões.

Outrossim, no presente estudo, foi possível identificar uma contraposição aos achados supracitados, visto que, durante a coleta de dados nos ambientes hospitalar e ambulatorial, observou-se que alguns indivíduos ainda ignoram as regras de Biossegurança. Com isso, constatou-se que muitas mulheres usam cabelos soltos durante seus atendimentos, unhas grandes e esmaltadas, sapatos inadequados e adornos, aumentando as chances de contaminação no ambiente de trabalho.

\section{Considerações Finais}

Mediante a atual pesquisa, foram evidenciadas as competências benéficas da atualização frequente das normas preventivas que refletem a adequada utilização de Equipamentos de Proteção Individual (EPI), bem como a redução dos riscos de acidentes. Assim, o presente estudo identificou resultados superiores ao averiguar que os profissionais e, principalmente, os acadêmicos da saúde apresentam mais domínio sobre as normas de biossegurança quando comparados às amostras de estudos recentes que contrariam a maior parte dos achados da pesquisa. Tal fato pode estar relacionado ao momento pandêmico vivenciado, o qual talvez tenha resultado em maior interesse e investimento na área da biossegurança.

Diante do cenário encontrado na pesquisa, ressalta-se a necessidade de educação continuada para os profissionais da área da saúde, visto que o grupo dos discentes apresentou contiguidade com a biossegurança. Sendo assim, é válido salientar a necessidade de continuidade de estudos acerca desta temática, sugerindo estratégias de intervenção para melhor orientação e ampliação do conhecimento sobre as normas de biossegurança. 


\section{Referências}

Azevedo, A. P. D.., Magno, H. T. S., Azevedo, L. S., \& Medeiros, F. P. (2021). Atitudes e práticas em biossegurança no centro de material e esterilização de um hospital terciário. Revista Eletrônica Acervo Científico, 20, e4985. https://doi.org/10.25248/reac.e4985.2021.

Bermúdez, J. M. G., Román, J. I. N., Álvarez, N. G. B., Córdova, C. A. A. (2021). Gestão de medidas de biossegurança para pessoal de enfermagem que trabalha na emergência área do Hospital General Norte de Guayaquil IESS Los Ceibos. Revista de Ciencias de La Salud, 3(1), 100-112. https://doi.org/10.47606/ACVEN/MV0064.

Cabral, F. W., \& Silva, M. Z. O. (2013). Prevenção e Controle de Infecções no Ambiente Hospitalar. Sanare, Sobral, 12(1), p. 59-70.

Chavarria, F. D. T. (2018). Nivel de conocimiento y práctica de medidas de bioseguridad: Hospital San José, 2016. Horiz. Med., 18(4), 42-49. http://dx.doi.org/10.24265/horizmed.2018.v18n4.06.

Cordeiro, J. F. C., Alves, A. P., Gir, E., \& Miranda, D. A. (2016). Uso de Equipamento de Proteção Individual em um serviço de Atenção Domiciliar. Cogitare Enferm., 21(3), p. 01-08.

Costa, K.P., Melo, A. C., Silva, B. B., \& Costa, I. A. (2020). Adherence to nursing biosafety measures in the intensive care unit: systematic review. Revista Nursing, 23(268), p. 4641-4645. https://doi.org/10.36489/nursing.2020v23i268p4636-4645.

Ferreira, L. A., Peixoto, C. A., Paiva, L., \& Silva, Q. C. G. (2017). Adesão às precauções padrão em um hospital de ensino. Rev. Bras. Enferm., 70(1), p.90-7. http://dx.doi.org/10.1590/0034-7167-2016-0138.

Ishaque, S., Arshad, A., Haider M. A., Fatima, F. (2021). Biosafety and Biosecurity of lab and hospital acquired infections. Biol. Clin. Sci. Res. J., e008. https://doi.org/10.47264/bcsrj0201008.

Islam, N., Kabir, H., Yusuf, A., \& Salam, B. (2020). Knowledge of Biosafety Measures among Laboratory Personnel at Tertiary Level Public Hospitals in Dhaka City. Bangladesh J. Infect Dis., 7(2), 49-56.

Júnior, A. S. A. et al. (2015). Risco biológico no contexto da prática de enfermagem: uma análise de situações favorecedoras. Revista de Epidemiologia e Controle de Infecção, 5(1), 01-05.

Languré, M. P. et al. (2016). Normas de Bioseguridad del Personal de Enfermería en una institución hospitalaria. Revista de Ciencias Biológicas y de la Salud.

Lima, R. J. V. et al. (2017). Agentes biológicos e equipamentos de proteção individual e coletiva: conhecimento e utilização entre profissionais. Rev. Pre. Infec. e Saúde, 3(1), 23-28.

Loro, M. M.; \& Zeitoune, R. C. G. (2017). Collective strategy for facing occupational risks of a nursing team. Rev. Esc. Enferm., 51(1), 1-8.

Ma, H. et al. (2020). Hospital biosecurity capacitation: Analysis and recommendations for the prevention and control of COVID-19. Journal of Biosafety and Biosecurity, 2(1), 5-9.

Marreiro, L. A. A et al. (2019). Medidas de biossegurança e a relação com os acidentes ocupacionais na enfermagem hospitalar: uma revisão integrativa. CONAPESC, 1-12.

Ministério da Saúde. (2010). Biossegurança em saúde: prioridades e estratégias de ação. Organização Pan-Americana da Saúde.

Morais, R. L. G. et al. (2017). Conhecimentos e condutas de biossegurança entre docentes de enfermagem. J. res.: fundam. care. online, 9(1), $137-143$.

Passos, E. A. D.; \& Marziale, M. H. P. (2020). Conhecimento e atitudes de profissionais de enfermagem de um hospital paulista frente às precauções padrão. Cogitare enferm.

Pimentel, B. J. et al. (2015). Manual de Biossegurança: Fisioterapia. Centro Universitário CESMAC.

Pires, Y. M. S.; Araújo, V. L. L.; \& Moura, M. C. L. (2019). Saúde do trabalhador em ambiente hospitalar: Mapeando riscos e principais medidas de biossegurança. Rev. UNINGÁ, 56(2), 115-123.

Rocha, T. H. L. et al. (2020). Falhas no uso de equipamentos de proteção individual pelos profissionais de saúde: revisão de literatura. Revista Eletrônica Acervo Saúde, 12(1), 1-10.

Santos, P. B. D. et al. (2017). Análise do conhecimento em biossegurança de acadêmicos formandos da área da saúde. Revista UNINGÁ, 53(1), 45-50.

Santos, T. H. M. et al. (2021). Biosafety: physiotherapy students' knowledge about techniques and behavior in cross-infection control. Jacarezinho, PR.

Silva, O. M. et al. (2022). Biosafety measures to prevent COVID-19 in healthcare professionals: an integrative review. Rev. Bras. Enferm., 75(1).

Sousa, D. S. et al. (2021a). Respiratory functional profile of children with COVID-19 during the hospitalization phase. Research, Society and Development, 10(10), e573101018946.

Sousa, D. S. et al. (2021b). Impact of signs and symptoms of urinary incontinence on the quality of life of women practicing musculation in the State of Sergipe. Research, Society and Development, 10(10), e598101018609

Sousa, D. S. et al. (2021c). Scientific and technological prospection study on Myracrodruon urundeuva (aroeira do sertão) and bacterial resistance. Research, Society and Development, 10(11), e138101119505.

Teixeira, P. (2010). Biossegurança: uma abordagem multidisciplinar. (2a ed.), Editora FIOCRUZ.

Teixeira, R. D. C. et al. (2020). Uso de medidas de Biossegurança por profissional fisioterapeuta. Cad., Edu. Saúde e Fis., 7(14), 1-9.

Vasconcelos, R. O. et al. (2017). Adesão à higienização das mãos pela equipe de Enfermagem em Unidade de Terapia Intensiva. Enferm. Glob., 50(1), 446461. 